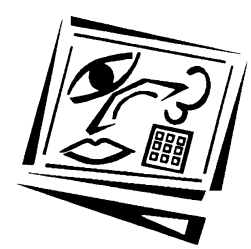

\title{
Multimedia based enhancement of the science of oenology in the distance education learning environment
}

\author{
Paul K. Bowyer \\ The University of Adelaide

\section{Christopher L. Blanchard} \\ Charles Sturt University
}

\begin{abstract}
Multimedia has been investigated regarding its utility as an enhancement mechanism, primarily for distance education students in the first year university course Wine Science 1 at Charles Sturt University. The resource consisted of a series of QuickTime movies outlining oenological chemical analysis experiments to be conducted during the block teaching, on campus portion of the course. They were created using Apple Computer's iMovie software and were delivered via $\mathrm{CD}$ as a new component of the print based materials package commonly used in distance education supported courses. $80 \%$ of the students were able to make use of the multimedia files to prepare for the practical component of the course before on campus attendance. When surveyed regarding the value of this learning resource enhancement, the vast majority of these students agreed that effective learning, understanding and, notably, relaxation were all significantly enhanced.
\end{abstract}

\section{Introduction}

Multimedia, defined as a combination of some or all of the elements of text, graphics, animation, sound and video using a computerised platform (Barron and Orwig, 1995), is becoming more widely recognised as an effective enhancement mechanism for education, in concert with the continual expansion of the technological arena. Whilst there is little doubt that the visual-spatial learning methodology is of great importance to many learners (Gardner, 1983), the relative ease with which education professionals can now create and utilise multimedia files has opened the door for extensive development and investigation. This change in educational methodology is fuelled by the growing requirement for educators to be ever more flexible and engage modern technology in their 
teaching (McNamara and Strain, 1997), coupled with projected cost advantages in terms of both staff and consumable logistics (Dewhurst et al, 1994).

Multimedia based learning resources find particularly effective application in the physical science of chemistry (Baker and Taylor, 1972; Burden 1993), which remains the basis for many courses within university programs. Trindade et al (2002) postulate that this is due to a cooperative marriage between learning style and mode of instruction, whilst other authors (Gregory and Stewart, 1997; Calverley et al, 1998; McCarthy, 1989; Kozma, 1991; Harwood and McMahon, 1997) maintain that the learner centred nature of these devices appeals to students with disparate academic histories. Further, the ability of a student to combine practical experimentation and graphical simulation is argued by Markham (1998) to facilitate associative knowledge through the employment of mental imagery. Beyond these arguments, one of the fundamental appeals of multimedia based education is its ability to activate the student's imagination through its relative novelty as an educational tool (Whalley, 1995).

Although both World Wide Web (WWW) and CD methods may be used for the delivery of multimedia devices, the latter is regarded by Gooley et al (1994) and others (such as Brooks and Brooks, 1996) to be superior due to advantages in transportation, storage capability and cost effectiveness. The basic requirements of a $\mathrm{CD}$ learning resource are faultlessness in execution and user friendliness (Lyall and McNamara, 2000). The same authors also recommend that CDs be used as alternatives to, rather than substitutes for, traditional educational devices to cater for the range of differing student learning modalities between traditional and progressive approaches. Rodrigues et al (1999) state that the main advantages of CDs lie in strong concept development, support for different learning styles, the development of knowledge linkages and the transfer of learning control to the learner. These arguments provide substantial impetus for the implementation of $\mathrm{CDs}$ as distance educational devices, especially considering that they do not confer additional access and service provider costs onto the user.

\section{Distance education}

Undertaking a distance education (DE) program from a remote location is both mentally and logistically challenging due to the physical separation of teacher and learner. Associated with these difficulties are the inherent elements of uncertainty and anxiety that any student studying in this manner must overcome. Although the literature demonstrates that the difficulties of the transmission of information and content are key factors 
in DE attrition rates (McLoughlin 1999; Morgan \& Tam 1999; Ozga \& Sukhnanden 1998), we postulate that the problems of uncertainty and anxiety also play a large part in attrition rates in undergraduate programs.

In the Level 1 course Wine Science 1, a compulsory course within Charles Sturt University's Wine Science, Viticulture and Winegrowing programs, the basic chemical analyses associated with quality control in the production of wine are examined in detail. The course is offered in internal (full time) and external (distance education, part time) modes, with the majority of students by far opting for the latter. The course is heavily based on chemistry, yet many of the students have only a minor exposure to chemistry prior to commencement and can find obtaining a suitable grasp on the course materials rather difficult, especially given the limited duration of face to face teaching in distance education courses. The highly visual and symbolic natures of chemistry courses make them prime targets for multimedia based enhancement (Burden, 1993), especially for distance education students.

As with most chemistry based courses, Wine Science 1 has a substantial practical component. In order to complete this component, students attend a "residential school" on campus over a four day period in the midsemester break, typically in September. Whilst at the residential school the students receive both tutorial tuition on the laboratory exercises and laboratory practical time, totalling 7 and 15 hours respectively over the four day period. At the conclusion of the residential school the students are required to sit a written examination to explore their depth of understanding of not only the method of execution of the laboratory exercises, but also of the underlying chemical principles upon which the experiments are constructed.

A further complication of the residential school learning environment is that insufficient equipment is available for all students to perform the same experiment at the same time. This requires that the students have a firm understanding of all procedures that they will be performing over the four day school, before they arrive on campus.

In contrast, internal students have a more relaxed timetable, comprising weekly laboratory sessions of three hours over a ten week period, coupled with weekly half hour tutorials, in which to develop a comprehensive understanding of the laboratory exercises. This totals 30 hours of laboratory time, which is double the allotment for external students. This simple mathematical disparity, in concert with the highly condensed timeframe through which the external students must work, provided the impetus for the development of a learning resource that would generate an avenue for greater equality in the respective learning modes. 
The Wine Science 1 course has several assessment items due to the wide span of topics and theoretical and practical studies encompassed. The course mark is calculated by simple arithmetic combination of two major components: the residential school mark and the final exam mark, weighted $60 \%$ and $40 \%$ respectively. This weighting emphasises the importance of the practical component of the course. The residential school component is assessed in three segments, comprising the laboratory exercise mark, the practical theory examination and a calculations examination, weighted 50\%, 30\% and 20\% respectively. Thus, in terms of contribution of each component to the final course mark, the following apply:

$\begin{array}{ll}\text { Laboratory exercise mark } & 30 \% \\ \text { Practical theory examination } & 18 \% \\ \text { Calculations examination } & 12 \% \\ \text { Final examination } & 40 \% \\ \text { Total course mark } & 100 \%\end{array}$

\section{Multimedia based enhancement}

An obvious way to approach the main problems of limited time and unlimited anxiety which face DE students in the Wine Science 1 course was to develop a resource to show the students both what the residential school would entail and to illustrate in detail the chemical experiments that they would be performing. Since the students receive a print mail package at the commencement of semester they possess the laboratory manual before attending the residential school, so there was no requirement for great detail to be provided. Additionally, if the resource could be accessed at any time, for any duration and any number of times, and at no cost, the nature of the residential school could be inverted, changing from a teacher centred to a learner centred, constructivist experience (Squires, 1999). Cost effectiveness was a strong requirement, along with transportability and other attributes that have already been noted.

Since DE students are typically concerned with the efficiency of their learning (Lyall and McNamara, 2000), a CD was seen to possess all required features.

\section{Wine Science 1 CD}

Students working in pairs at the residential school, examining via chemical means several parameters of a wine or juice sample, perform a minimum of nine experiments. The experiments conducted are hydrometry, refractometry, $\mathrm{pH}$, titratable acidity, sulfur dioxide level by both the 
aspiration/oxidation and iodometric methods, residual sugar determination, acetic acid level and a malic acid determination by thin layer chromatography. In each case the experiment was performed by Dr Bowyer, following the laboratory manual procedure, whilst being captured using a digital video camera (Figure 1). Key points and difficulties were highlighted in each case, such as colour changes or event timing (Figure 2). The footage was then imported into iMovie and edited to produce a seamless videographic illustration of each experiment.

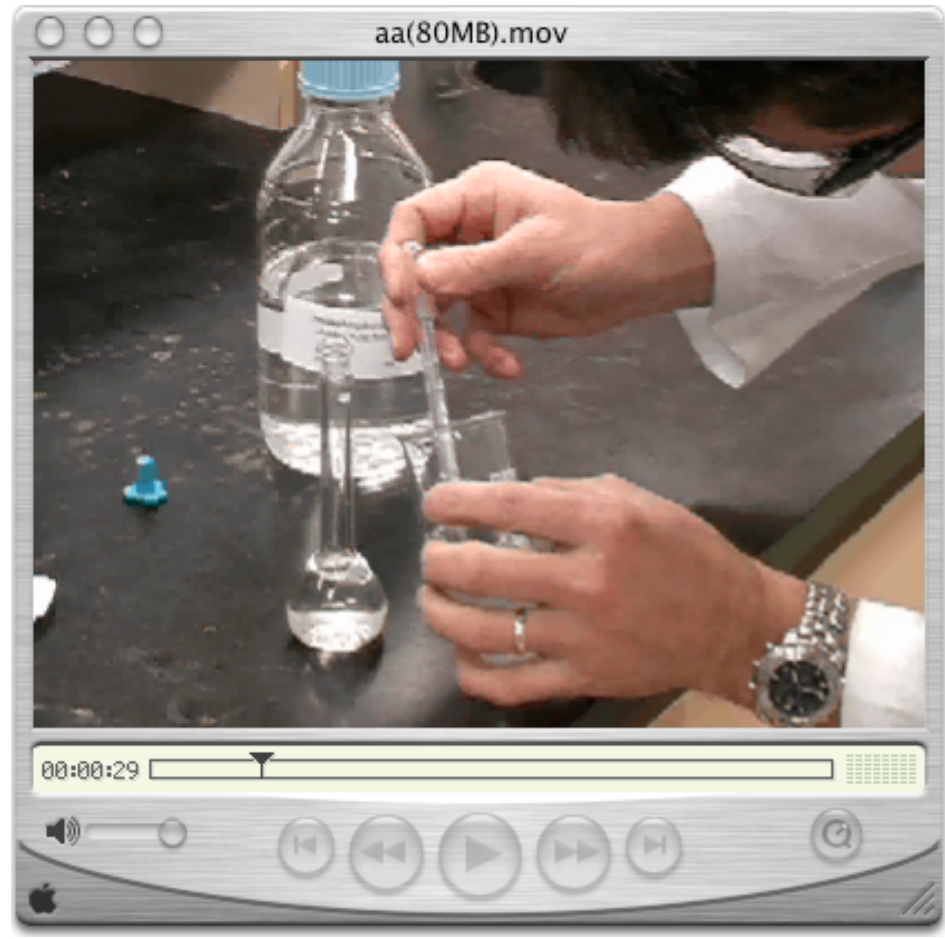

Figure 1: A still image taken from the QuickTime ${ }^{\mathrm{TM}}$ movie illustrating a part of the laboratory procedure for measuring ascorbic acid levels in white wine.

Voiceover instruction was added to complement the printed laboratory manual, in addition to suitable title slides to highlight specific points in each procedure (where required). In the case of more theoretically challenging experiments (such as the iodometric titration experiment), a short tutorial on the underlying principles of the procedure was provided preceding the experimental footage. 


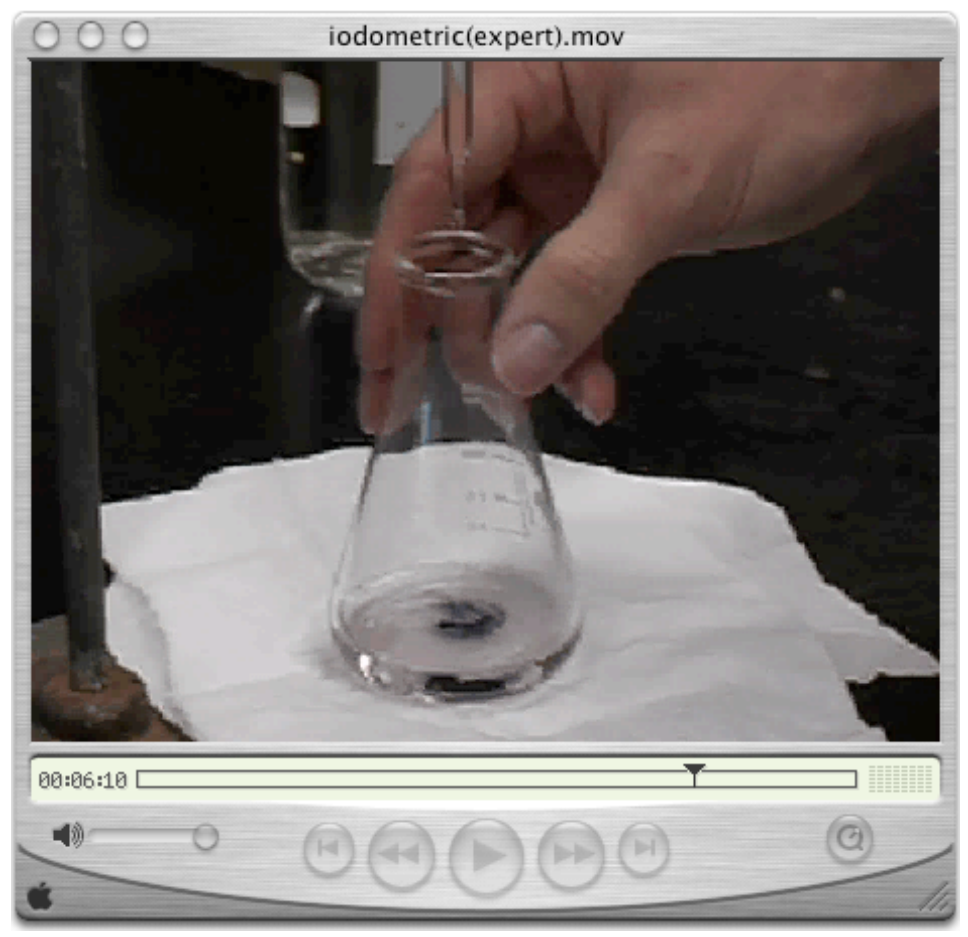

Figure 2: A still image taken from the QuickTime movie illustrating a technical component of the laboratory procedure for measuring preservative levels in wine, showing the colour of the indicator at the end point of the experiment.

On reviewing the videos the author noted that an element of interest was absent, mainly due to the somewhat sterile nature of the presentations. As noted by Whalley, (1995), engagement of the student's imagination is desirable. This obstacle was alleviated in simple fashion by adding low level background loop music, which was also obtained at no cost from Apple's website and from the Internet.

The files were exported to the cross-platform QuickTime format (Figures 1 and 2) in four different levels of resolution. From this pool of files, selected examples were placed onto $\mathrm{CD}$, with the more complex experiments presented in higher resolution to maximise the use of the available storage volume. A short video on laboratory safety was added in addition to an introductory title page in HTML format, and an automatic start function was added for users of Microsoft's Windows operating systems. To cater for those students without a computer, the edited files were also exported 
back to the video camera and then onto VHS cassette. Three copies were made and placed into the CSU Library, where they could be mailed out to DE students at no charge on request. The VHS cassettes were used 12 times in the year following production, indicating a notable level of computer inaccessibility on the part of the students.

The CD was labelled with the course name and university logo and mailed out as a part of the print based learning package for the first time in semester 2, 2002.

The authenticity of the multimedia files provides not only realistic demonstrations of the procedures (Bosco, 1984), but also provides a degree of motivation due to the novel method of delivery, a factor which has been noted previously (Kearney and Treagust, 2001; Beichner, 1996; Rubin et al, 1996; Laws and Cooney, 1996; Gross, 1998). Additionally, the files can be viewed on a random and frame by frame basis if desired, which is not possible with simple conventional video due to the degradation of the arrested video image (Kearney and Treagust, 2001).

Several students who encountered technical difficulties contacted Dr Bowyer via a web based forum or via email, who then provided technical advice on how to overcome problems, where possible. Typically, this involved instruction on how to navigate through the directory structure of the CD to access the files directly instead of using a web browser from the opening title page of the CD.

\section{Student evaluations}

At the commencement of the residential school the students were given a detailed tutorial of the chemical principles behind the experiments over a three hour period, using the CD, a computer and a data projector. In addition to providing a means of relating practice to the chemical principles involved in the experiments, this also provided the services of the $C D$ to those students who were unable or unwilling to employ the resource previously. The students then undertook the normal residential school program, commencing that afternoon with experiments. At the conclusion of the residential school the students were surveyed with respect to several issues, all of which related to the perceived value of the $\mathrm{CD}$ as a learning resource.

100 distance education students attended the residential school in 2002. The results of the survey are presented here.

For statements that required the students to respond indicating a degree of agreement or disagreement rather than simply replying in the affirmative or negative, a scale from 0 to 7 was used in the manner illustrated in Table 
1. The exception to this system was statement 7 , where students were asked to provide a response on a scale covering the following range: very highly $(\mathrm{VH}$, point value 5$)$, highly $(\mathrm{H}, 4)$, undecided $(\mathrm{U}, 3)$, low $(\mathrm{L}, 2)$, very low $(\mathrm{VL}, 1)$ and not applicable (NA, 0$)$.

Table 1: The assigned point values for student responses on the questionnaire for statements 2-6

\begin{tabular}{|c|c|}
\hline Response & Assigned point value \\
\hline Very strongly agree & 7 \\
\hline Strongly agree & 6 \\
\hline Agree & 5 \\
\hline Uncertain & 4 \\
\hline Disagree & 3 \\
\hline Strongly disagree & 2 \\
\hline Very strongly disagree & 1 \\
\hline Not applicable & 0 \\
\hline
\end{tabular}

For each statement the average response score was calculated numerically and also expressed as a percentage of the maximum possible response. These results are given in Table 2. Students were also asked to provide comments, both positive and negative, and these, where pertinent, are presented.

Table 2: Tabulated responses for the evaluation statements 2-7.

Responses for statement 7 were scored according to the following scale: 0 (not applicable), 1 (very low), 2 (low), 3 (undecided, 4

(highly) and 5 (very highly).

\begin{tabular}{|c|c|c|c|c|c|c|c|c|c|c|}
\hline \multirow[b]{2}{*}{ Statement } & \multicolumn{8}{|c|}{ Score (Response \%) } & \multirow[b]{2}{*}{ Mean } & \multirow{2}{*}{$\begin{array}{c}\% \text { of } \\
\text { max. } \\
\text { response }\end{array}$} \\
\hline & 0 & 1 & 2 & 3 & 4 & 5 & 6 & 7 & & \\
\hline 2 & - & - & - & - & $\begin{array}{c}1 \\
(1 \%)\end{array}$ & $\begin{array}{c}25 \\
(31 \%)\end{array}$ & $\begin{array}{c}31 \\
(39 \%)\end{array}$ & $\begin{array}{c}23 \\
(29 \%)\end{array}$ & 6.0 & 85 \\
\hline 3 & - & - & - & - & $\begin{array}{c}1 \\
(1 \%)\end{array}$ & $\begin{array}{c}30 \\
(38 \%)\end{array}$ & $\begin{array}{c}25 \\
(31 \%)\end{array}$ & $\begin{array}{c}24 \\
(30 \%)\end{array}$ & 5.9 & 84 \\
\hline 4 & - & - & - & - & $\begin{array}{c}6 \\
(8 \%) \\
\end{array}$ & $\begin{array}{c}29 \\
(36 \%)\end{array}$ & $\begin{array}{c}23 \\
(29 \%) \\
\end{array}$ & $\begin{array}{c}22 \\
(28 \%) \\
\end{array}$ & 5.8 & 82 \\
\hline 5 & - & - & - & $\begin{array}{c}1 \\
(1 \%)\end{array}$ & $\begin{array}{c}1 \\
(1 \%)\end{array}$ & $\begin{array}{c}29 \\
(36 \%)\end{array}$ & $\begin{array}{c}24 \\
(30 \%)\end{array}$ & $\begin{array}{c}25 \\
(31 \%)\end{array}$ & 5.9 & 84 \\
\hline 6 & - & - & - & - & $\begin{array}{c}2 \\
(3 \%)\end{array}$ & $\begin{array}{c}9 \\
(11 \%)\end{array}$ & $\begin{array}{c}23 \\
(29 \%)\end{array}$ & $\begin{array}{c}46 \\
(58 \%)\end{array}$ & 6.4 & 92 \\
\hline 7 & - & - & - & $\begin{array}{c}4 \\
(5 \%) \\
\end{array}$ & $\begin{array}{c}34 \\
(43 \%)\end{array}$ & $\begin{array}{c}42 \\
(53 \%)\end{array}$ & $\begin{array}{r}n \\
\text { appl }\end{array}$ & $\begin{array}{l}\text { ot } \\
\text { cable }\end{array}$ & 4.5 & 90 \\
\hline
\end{tabular}




\section{Analysis of responses and discussion}

\section{Question 1: Did you use the videos to prepare in advance for the residential school?}

$80 \%$ of the students were able to study the CD before attending the residential school. Of the $20 \%$ who did not use the CD, 11 people $(55 \%)$ cited technical difficulty. It is unclear what the exact natures of all of these technical difficulties were, however given the enormous range in computing power of personal computers due to technological advances over the last decade, it is not surprising that some users experienced difficulties. In a few cases these difficulties were overcome via communication with Dr Bowyer. Three people offered no reason, two claimed that they had no time, one stated that the valuable content of the CD was not realised until it was seen on display at the residential school, one claimed to be sufficiently experienced in the procedures already and one did not get a copy of the CD due to an enrolment aberration. One student also stated that he/she was sufficiently "satisfied with the printed laboratory manual" not to examine the $\mathrm{CD}$, which parallels an observation made by Lyall and McNamara (2000) relating to the perceived "risk" of undertaking a new learning method.

\section{Student comments}

Student comments are direct transcripts (excepting additions for clarity made by the authors, which are indicated by square parentheses) and so contain spelling and grammatical errors.

- Did not [see] video until arriving at res school because I couldn't get the $\mathrm{CD}$ to play on my computer. However, seeing it on video at res school greatly increased my confidence to complete prac work to a high standard.

- Very useful tool in terms of time management \& increased understanding of subject prior to arrival at res school. Enabled a sound understanding of all subject components, which isn't possible in other units without direct lab experience.

Statements 2-7 relate only to those 80 students who used the $C D$ to prepare for the residential school.

Statement 2: The videos helped me feel more relaxed in preparing for the residential school

$29 \%, 39 \%$ and $31 \%$ of students responded in agreement to this statement in levels corresponding to very strongly agree (VSA), strongly agree (SA) and agree (A) respectively. One person only of the 80 respondents remained 
uncertain with regards to the value of the resource in reducing preresidential school anxiety. This person cited "some technical difficulty", and so perhaps was unable to extract the full benefit from the CD.

The mean response to this statement was 6.0 , corresponding to $85 \%$ of the possible maximum. No responses were made in the negative at any level of disagreement.

\section{Student comments}

- For someone that had no lab experience they were invaluable in helping to visualise and conceptualise the pracs before coming to res school. Without them it would have been much more daunting.

- Reviewing [the] videos made you feel more confident in attending and understanding every step of practicals performed. I could analyse and learn different techniques used in performing a practical properly, which is important - just reading does not tell all (what is exactly happening during [the] reaction). I would like some more of this if [the] uni wants to upgrade its learning facilities. I give 10/10 Dr Bowyer.

\section{Statement 3: The videos helped to better prepare me for effective learning during the residential school}

$30 \%$ of students agreed very strongly with this statement, with $31 \%$ strongly agreeing and 38\% agreeing. This result clearly demonstrates that the students felt that using the CD increased the level of efficiency of their learning, which is consolidated by a mean response of 5.9 ( $84 \%$ of the possible maximum). No responses were made in the negative at any level of disagreement.

\section{Student comments}

- For people that had had no exposure to lab equipment and process it helped in time saving once in the lab allowing more time to concentrate on the theory behind the experiments.

- Excellent resource for people not familiar/inexperienced with equipment \& analysis performed. Enhanced confidence and allowed more efficient use of my time.

- I believe these videos/CDs are extremely important for DE students, so that the few days spent at res school are optimised.

\section{Statement 4: The videos enhanced my overall learning during the residential school in this subject}

Student responses encompassed a slightly more negative spread with regards to the question of the enhancement of overall learning during the 
residential school, with the following responses recorded: VSA (28\%), SA $(29 \%), \mathrm{A}(36 \%)$ and $\mathrm{U}(8 \%)$, the latter figure corresponding to 6 students out of 80 .

This question was specifically asked to gauge the students' perception of the depth of impact that the learning resource had on comprehension of the laboratory material as a whole, rather than just the specific segment of actually performing the experiments that it was primarily aimed at enhancing. It remains the authors' hypothesis that improved understanding in one area of a course can positively impact on the attitude of the student towards the remainder of the material being presented. The number of students agreeing in all levels of the affirmative would appear to support this theory.

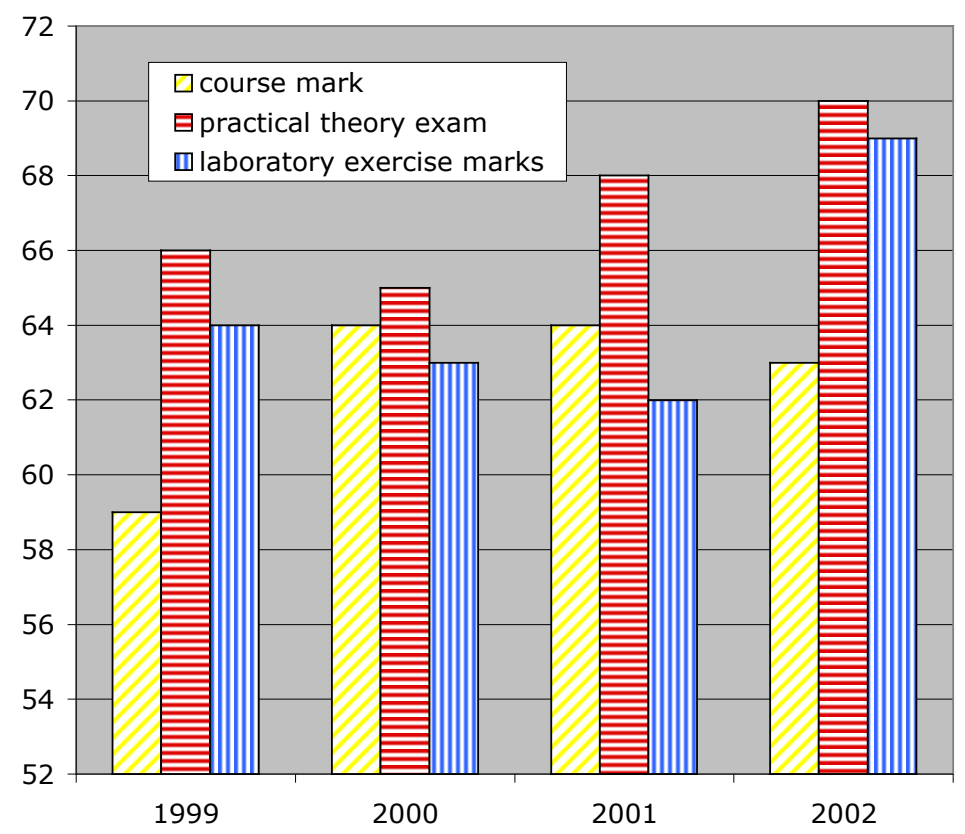

Figure 3: A histogram indicating student marks for the overall course, the practical theory examination and the actual laboratory exercise marks from 1999-2002. The CD was used for the first time in 2002.

An analysis of the marks obtained by the students over the years 19992002 is presented in Figure 3. The graph indicates that comprehension of the theoretical concepts underpinning the laboratory exercises has increased with time, whilst the average course mark is approximately 
static. Most importantly, the actual performance level of execution of the laboratory experiments (the primary reason for the development of the CD) was seen to notably increase, as can be seen in Figure 3 by examining the laboratory exercise mark aggregates (blue column, vertical lines): In 2001 the average mark gained for the laboratory exercises was $62 \%$, whilst in 2002, after the introduction of the CD, this mark increased to $69 \%$, corresponding to an increase in one year of $11 \%$.

The mean response of 5.8 (82\% of the possible maximum) again is indicative of general student support for the statement.

\section{Student comment}

- At the moment much of the online information available for CSU subjects is just a reprint of the subject guide or notes placed on the forum by the lecturer. As DE students we feel disadvantaged by the lack of face-to-face contact with demonstrators/ lecturers. Videos, CDs and online information needs to be dynamic and informative to negate the disadvantage and allow DE students to feel more a part of CSU.

\section{Statement 5: The videos significantly helped my understanding of the laboratory exercises}

$31 \%$ or students gave the response of VSA, 30\% gave SA and $36 \%$ agreed with the statement. One student was undecided and one disagreed, although the latter student offered no comments on the CD and was supportive in responses to the other sections of the survey. The laboratory exercise marks and practical exam marks shown in Figure 3 suggest improved outcomes in accordance with the students' very positive views on Question 5. Coupled with a mean response of 5.9 (84\% of maximum), these data indicate that the driving force for the creation of the resource had been satisfied.

\section{Student comment}

- Spatial/visual learning is often a large portion of our learning skill. This can only be met by such means as video presentations. It is an excellent way to understand concepts initially and can provide the means to repeat playback until fully understood.

\section{Statement 6: I would like to see similar learning resources developed in other subjects in my course}

This statement was deemed to represent a particularly important facet of the survey due to its obvious ramifications for the future development and implementation of this type of learning resource in other courses and programs offered at tertiary level in Australia. More than half of the 
students $(58 \%)$ returned the maximum response possible in agreement (VSA) with this statement, with a further 29\% strongly agreeing. $11 \%$ of students simply agreed, whilst 3\% (2 students) were undecided.

This statement drew the most conclusive response of all items in the survey, with a mean response of 6.4 , corresponding to $92 \%$ of the possible maximum. This result clearly indicates that distance education students in the Level 1 course Wine Science 1 at CSU would like to see this type of learning resource become commonplace in their learning environment.

Importantly, no students were negative in their response to this statement, which strongly suggests that they value this type of learning resource as an enhancement to traditional print based distance education learning materials.

\section{Student comment}

- Please more videos /CD-ROM for any lab subject or to clarify areas where visual imagery helps! $80 \%$ of people use predominantly visual input for learning \& moving visual is even more effective at getting the point across.

\section{Statement 7: I would rate the videos as a learning resource for this subject}

More than half of the students (53\%) rated the CD "very highly" as a learning resource. A further 43\% rated the videos "highly", whilst 5\% (4 students) were undecided as to how they valued the resource. No students rated the CD as "low" or "very low", clearly indicating that no students thought it was of no educational benefit. A mean response of 4.5 (90\% of the possible maximum) is highly indicative that the DE students undertaking this course gain significant educational benefit from the use of this resource.

\section{Student comment}

- Videos were very worthwhile, made the lab sessions a bit more enjoyable instead of just trying to rush through. Would be very useful in other subjects.

- Videos worked very well - were clear and well done. Software was easily obtained, instructions were straightforward and simple to use.

- Excellent resource - highly commend initiative. Would recommend considered for other subjects. Certainly made lab time more efficient not being confronted with equipment for first time. Alleviates some of the intimidation of being a DE student on limited time. 


\section{Conclusions}

Distance education students undertaking the Level 1 chemistry based course Wine Science 1 at Charles Sturt University gain significant educational enhancement from the development and inclusion of multimedia based learning resources when coupled with traditional print based materials. Not only do students rate the value of this type of educational tool very highly, they also experience a significantly increased depth of understanding of the materials and reduced pre-residential school anxiety. The actual performance level of the experiments conducted during the residential school underwent a significant increase after the implementation of the $\mathrm{CD}$, clearly indicating that the strategic goal driving the creation of the learning resource was attained.

\section{Acknowledgments}

The authors wish to thank Ronnie Cay of Charles Sturt University's Centre for Enhancing Learning and Teaching for her assistance in the final stages of production of the CD.

\section{References}

Baker, S. and Taylor, L. (1972). The relationship of visualisation skill to achievement in freshman chemistry. Journal of Chemical Education, 49, 775-777.

Barron, A. E. and Orwig, G. W. (1995). Multimedia Technologies for Training. Libraries Unlimited Inc. Englewood, CO.

Beichner, R. (1996). The impact of video motion analysis on kinematics graph interpretation skills. AAPT Announcer, 26, 86.

Bosco, J. (1984). Interactive video: Educational tool or toy? Educational Technology, 24(3), 13-19.

Brooks, H. B. and Brooks, D. W. (1996). The emerging role of CD-ROMs in teaching chemistry. Journal of Science Education and Teaching, 5(3) 203-215.

Burden, F. R. (1993). Computer aided instruction: Authoring tools for chemistry teaching. Chemistry in Australia, February, 72-3.

Calverley, G., Fincham, D. and Bacon, D. (1998). Modernisation of a traditional physics course. Computers in Education, 31(2), 151-169.

Dewhurst, D. G., Hardcastle, J., Hardcastle, P. T. and Stuart, E. (1994). Comparison of a computer simulation program and a traditional laboratory practical class for teaching the principles of intestinal absorption. Advances in Physiology Education, 12(1), 95-103. 
Gardner, H. (1983). Frames of Mind: The Theory of Multiple Intelligences. Basic Books, Cambridge.

Gooley, A., Towers, S. and Dekkers, J. (1994). CD-ROM for education and training in rural and remote areas. In T. Evans and D. Murphy (Eds), Research in Distance Education, 4, 127-136.

Gregory, J. R. and Stewart, M. F. (1997). Production of a multimedia CAL package in basic physics. Physics Education, 32(5), 332-339.

Gross, M. (1998). Analysis of human movement using digital video. Journal of Educational Multimedia and Hypermedia, 7(4), 375-395.

Harwood, W. S. and McMahon, M. M. (1997). Effects of integrated video media on student achievement and attitudes in high school chemistry. Journal of Research in Science Teaching, 34(6), 17-631.

Kearney, M. and Treagust, D. F. (2001). Constructivism as a referent in the design and development of a computer program using interactive digital video to enhance learning in physics. Australian Journal of Educational Technology, 17(1), 64-79. http: / / www.ascilite.org.au/ajet/ajet17 / kearney.html

Kozma, R. B. (1991). Learning with media. Review of Educational Research, 61(2), 179211.

Laws, P. and Cooney, P. (1996). Constructing spreadsheet models of MBL and video data AAPT Announcer 2532.

Lyall, R. and McNamara, S. (2000). Learning tool or potplant stand? Students' opinions of learning from a CAL program in a distance education context. Australian Journal of Educational Technology , 16(2), 126-146. http: / / www.ascilite.org.au/ajet/ajet16/lyall.html

Markham, U. (1998). The elements of visualisation. Element, Boston.

McCarthy, R. (1989). Multimedia: What the excitement's all about Electronic Learning, 8, 26-31.

McLoughlin, C. (1999) The implications of the research literature on learning styles for the design of instructional material. Australian Journal of Educational Technology, 15(3), 222-241. http: / / www.ascilite.org.au / ajet/ajet15/mcloughlin.html

McNamara, S. and Strain, J. (1997). All you need is ...? Assumptions and realities in building multimedia learning environments and resources. Proceedings ASCILITE'97, Perth: Curtin University of Technology. http:/ / www.ascilite.org.au/conferences/perth97/papers/Mcnamara/Mcnamara.html

Morgan, C. K. and Tam, M. (1999). Unravelling the complexities of distance education student attrition. Distance Education, 20(1), 96-108.

Ozga, L. and Sukhnandan, L. (1998). Undergraduate non-completion: Developing an explanatory model. Higher Education Quarterly, 52(3), 316-333. 
Rodrigues, S., Chittleborough, G., Gooding, A., Papadimitropoulos, T., Varughese, V. K., Kemp, S., Sadler, J., Gilmour, M., McKenna, B. and Helme, S. (1999). Using CD-ROMs in teaching science: Findings from a small scale study. Australian Journal of Educational Technology, 15(2), 136-147. http: / / www.ascilite.org.au/ajet/ajet15/ rodrigues.html

Rubin, A., Bresnahan, S. and Ducas, T. (1996). Cartwheeling through CamMotion. Communications of the ACM, 39(8), 84-85.

Squires, D. (1999). Educational software for constructivist learning environments: Subversive use and volatile design. Educational Technology, 39(3), 48-54.

Trindade, J., Fiolhais, C. and Almeida, L. (2002). Science learning in virtual environments: A descriptive study. British Journal of Educational Technology, 33(4), 471-488

Whalley, P. (1995). Imagining with multimedia. British Journal of Educational Technology, 26(3), 190-204.

Paul K. Bowyer

School of Agriculture and Wine, Discipline of Wine and Horticulture

The University of Adelaide, Waite Campus

PMB1 Glen Osmond, South Australia 5064.

Email: Paul.Bowyer@adelaide.edu.au

Paul Bowyer has a background in chemistry and is currently a lecturer in Oenology at the University of Adelaide. After completing his doctorate at the University of New South Wales in 1996 he continued his research at the Australian National University and then at Universität Basel, Switzerland. In 1999 he accepted a position as Associate Lecturer in Wine Science at Charles Sturt University (CSU), and he was promoted to Lecturer in 2000. In 2001 he received a Faculty Teaching Excellence Award based, in part, on his pioneering efforts in the development of a multimedia enhanced teaching program.

Christopher L. Blanchard

School of Wine and Food Sciences

Charles Sturt University

Locked Bag 588, Wagga Wagga NSW 2678.

Email: cblanchard@csu.edu.au 